\title{
Negritud, oralidad y carnaval en la narrativa afrodescendiente peruana del siglo XX (Gálvez Ronceros, Martínez y Charún-Illescas): hacia la conformación de un corpus autónomo
}

\author{
Negritude, Orality and Carnival in the Twentieth Century Peruvian \\ Afro-Descendant Narrative (Gálvez Ronceros, Martínez and \\ Charún-Illescas): Towards the Formation of an Autonomous \\ Corpus
}

\author{
Américo Mudarra Montoya \\ Universidad Nacional Mayor de San Marcos, Lima, Perú \\ Contacto: amudarram@unmsm.edu.pe \\ https://orcid.org/0000-0002-8008-7251
}

\section{Resumen}

La presente investigación aborda la obra de los tres principales referentes de la literatura afrodescendiente producida en el siglo XX en el Perú: Antonio Gálvez Ronceros (Monólogo desde las tinieblas), Gregorio Martínez (Canto de sirena) y Lucía Charún-Illescas (Malambo). Se propone analizar la obra en conjunto de estos tres autores con el objetivo de establecer los rasgos comunes que comparten. Se realiza un análisis comparativo de las estrategias discursivas y lingüísticas empleadas en estas obras que, en conjunto, comparten el objetivo común de problematizar las representaciones tradicionales del sujeto afroperuano por medio de una toma de conciencia lingüística de la naturaleza del objeto literario. Asimismo, se considera la importancia que tiene la tradición de la cultura cómico popular en las formas de la literatura carnavalizada descrita por Bajtín, en los universos ficcionales de las obras de estos autores, y no solo en la obra de Gregorio Martínez, como tradicionalmente se ha afirmado.

Palabras clave: Antonio Gálvez Ronceros; Gregorio Martínez; Lucía Charún-Illescas; Narrativa peruana; Literatura afrodescendiente; Negritud; Oralidad; Carnaval; Identidad

\begin{abstract}
This research deals with the work of the three main references of Afrodescendant literature produced in the $20^{\text {th }}$ century in Peru: Antonio Gálvez Ronceros (Monólogo desde las tinieblas), Gregorio Martínez (Canto de sirena) and Lucía Charún-Illescas (Malambo). It is proposed to analyze the work together of these three authors in order to establish the common features they share. A comparative analysis of the discursive and linguistic
\end{abstract}


strategies used in these works is carried out. Together, these three works share the common goal of problematizing the traditional representations of the Afro-Peruvian subject through a linguistic awareness of the nature of the literary object. Likewise, the importance of the tradition of popular comic culture, under the forms of carnivalized literature described by Bakhtin, is considered in the fictional universes of the works of these authors, and not only in the work of Gregorio Martínez, as traditionally It has been affirmed.

Keywords: Antonio Gálvez Ronceros; Gregorio Martínez; Lucía CharúnIllescas; Peruvian Narrative; Afro-Descendant Literature; Negritude; Orality; Carnival; Identity

Recibido: 17.04.19

Aceptado: 23.09.19

\section{Introducción}

El presente trabajo propone, esencialmente, que las obras de Antonio Gálvez Ronceros (Monólogo desde las tinieblas), Gregorio Martínez (Tierra de caléndula y Canto de sirena) y Lucía Charún-Illescas (Malambo) constituyen una reflexión sobre la identidad afrodescendiente con base en la textura lingüística que emplean y la utilización del humor carnavalizado al que recurren. En los tres casos, dichos rasgos formales son esenciales para demarcar la identidad de los personajes. Cada obra, en tal sentido, establece combinaciones distintas de una serie de elementos similares. Estos rasgos singulares permiten establecer un corpus de textos que siguen ciertos patrones comunes y encuentran un propósito similar en el cuestionamiento de las estructuras de poder que someten a los sujetos afrodescendientes. Por ello, se puede hablar de una tradición de literatura afrodescendiente que constituye, en palabras de Antonio Cornejo Polar (1989), un sistema autónomo siempre en litigio con la literatura oficial y en abierta polémica con el canon literario. En este marco, es vital identificar los rasgos que diferencian a esta narrativa de producciones literarias anteriores.

Para explicar adecuadamente estas ideas, el desarrollo se encuentra dividido en cinco apartados. En el primero se ofrecen algunos de los rasgos comunes que caracterizaron la representación del sujeto afrodescendiente en 
la narrativa de Enrique López Albújar, antecedente indiscutible de la tradición estudiada en este trabajo. El propósito es evidenciar de qué forma el cuerpo define la identidad del sujeto afro representado en estas obras. Así, la caracterización del sujeto se acerca a lo que Marcel Velázquez (2005) ha definido como sujeto esclavista: un individuo determinado por una sexualidad exacerbada que provoca simultáneamente, según su género, deseo (por sus mujeres) y rechazo (hacia los varones), que son vistos como una amenaza para las mujeres blancas de la casa familiar. Aunque Velázquez estudia la obra de autores del siglo XIX, el esquema que propone se adecua a la estructura de sentido que impera en Matalaché (1973 [1928]) de Enrique López Albújar.

En el segundo apartado, el análisis se concentra en la primera edición de Monólogo desde las tinieblas (1975) de Antonio Gálvez Ronceros (2017). En este caso, el estudio expone dos directrices de este conjunto de relatos. Primero, se observa la manera en que Gálvez Ronceros construye la voz del sujeto afrodescendiente y la dota de una verosimilitud basada, principalmente, en el manejo del sonido. La voz de los personajes "suena" de manera similar a la vida real. Con esta obra de Gálvez Ronceros (2017) se consigue la representación de la oralidad del habla afrodescendiente (Cuba, 1999). En tal sentido, no solo se representan a los personajes, sino también su forma de hablar. Según varios autores (Cuba, 1999; Espino, 2010; Terán, 2008; Vich \& Zavala, 2004), la representación de la oralidad supone, aunque sea indirectamente, un gesto político que debe ser considerado en el análisis. Asimismo, representar la voz del otro subalterno implica también asumir una posición respecto al poder (Vich \& Zavala, 2004). La obra de Gálvez Ronceros, entonces, establece un posicionamiento respecto al discurso hegemónico sobre los afrodescendientes. Por otro lado, algunos de los relatos de Monólogo recurren al uso de un humor carnavalesco, que remite al universo de la cultura cómico popular que se asienta en prácticas ancestrales, como sostiene Mijaíl Bajtín (1988) en su clásico La cultura popular en la Edad Media y el Renacimiento. El contexto de François Rabelais. Estas referencias populares ya han sido estudiadas, parcialmente, por Víctor Quiroz (2013). Para el estudioso, la mayoría de los relatos recurren al uso de destronamientos, profanaciones y el uso de un lenguaje abiertamente obsceno 
y popular. Estos rasgos que pueden observarse en varios relatos definen una forma distinta de representación del sujeto afrodescendiente.

En el tercer apartado se estudia la novela Canto de sirena (1979 [1977]) de Gregorio Martínez. El análisis considera tres variables. Las dos primeras inciden en la representación del lenguaje oral del sujeto afrodescendiente y los vínculos que la novela establece con la tradición cómico popular. De forma similar a Gálvez Ronceros, en esta novela existe un esfuerzo narrativo por capturar la voz del sujeto de color. La novela de Martínez tiene como eje de enunciación a su protagonista, Candico (Candelario Navarro), y parodia, abiertamente, una serie de discursos, el religioso y el científico especialmente. Asimismo, reconstruye el tópico de la historia de vida que constituye uno de los motivos centrales de las narraciones realistas (Levin, 1974). Esta representación de la oralidad se complementa con el uso de un humor de rasgos carnavalescos. Son comunes también, en esta novela, al uso de elementos del realismo grotesco que postula Bajtín (1988). El cuerpo y lo escatológico constituyen los ejes de una visión rural del mundo que observa la realidad desde una perspectiva otra. Como se sabe, lo escatológico forma parte de la cultura popular y posee una significación que, aunque es histórica y se activa según los diferentes contextos que la enmarcan, arraiga en tradiciones ancestrales (Laporte, 1998; Werner, 2013). En la novela de Martínez, este elemento es esencial para definir un tipo de sujeto que se sabe distinto y, a partir de su singularidad, replantea las coordenadas de la realidad, que desemboca en una historia otra, donde las representaciones hegemónicas que sustentan la autoridad y el poder sobre lo negro quedan suspendidas o cuestionadas. Estos dos componentes, como han señalado Milagros Carazas (1998) y Gloria Macedo (2008), definen un tipo de narrativa que desborda la tipología de novela testimonial y problematiza el estatuto narrativo de la novela misma.

En el cuarto apartado se analiza la novela Malambo de Lucía CharúnIllescas (2001). Esta obra, aunque cronológicamente pertenece a otro momento de la narrativa peruana, posee rasgos comunes con las obras de Gálvez Ronceros y Martínez. No se trata solo de la representación de personajes de color. La 
novela de Charún-Illescas incorpora también, aunque en menor escala, elementos de la oralidad y del universo carnavalesco afro. De forma más específica, en Malambo operan elementos que pertenecen a la novela polifónica, definida según los parámetros de Mijaíl Bajtín (2012), que — como señala el teórico rusoarraiga en las formas del diálogo socrático, la sátira menipea y el carnaval. Una de estas nociones es el "umbral", que en la novela de Charún-Illescas resulta de suma importancia porque permite definir el universo representado y problematizarlo. Asimismo, en esta novela es recurrente la alusión al cuerpo como componente esencial de la identidad de los sujetos de color. En algunos pasajes, la representación corporal posee alusiones al realismo grotesco planteado por Bajtín. Se trata de corporalidades excesivas, cuyas dimensiones aparecen erotizadas o constituyen una "agresión" para los sujetos blancos en la narración. Dentro de esta perspectiva, la posición de la mujer afrodescendiente es crucial, ya que, en la novela, ella es uno de los seres que conserva la tradición ancestral. Estos elementos confluyen en el proyecto narrativo de Charún-Illescas, cuyo principal objetivo consiste en insertarse en el discurso histórico y construir un posicionamiento que problematice la versión oficial. La apuesta de la narradora es más ambiciosa que la de sus predecesores. En su caso, no se trata de crear una visión alternativa, sino de deconstruir y reconstruir la versión oficial a partir de una perspectiva inédita, que considere elementos de la tradición africana y afroperuana.

Por último, en la parte final de este trabajo, se sintetizan las ideas centrales de la investigación. A modo de conclusiones, se establece que es posible definir elementos compartidos en la obra de estos tres narradores que van más allá de la representación de los sujetos de color. Dichos aspectos compartidos son, básicamente, dos: la representación de la oralidad y la presencia de elementos de la cultura cómico popular carnavalizada, o derivados de ella como la noción de "umbral". En cada una de las obras estudiadas, la presencia de estos elementos confluye en un propósito de índole político, ya que, a su manera, intentan problematizar la representación del sujeto de color, así como los discursos sociales que han justificado su sometimiento. Las discursividades con las que se establece una relación dialógica (Bajtín, 1991) varían según cada una 
de las obras. En Gálvez Ronceros, el discurso racista, que ha validado prácticas de discriminación y violencia, es puesto en cuestión innumerables veces por medio del humor popular. En Martínez, por otro lado, los discursos religioso y científico son parodiados desde una perspectiva que empodera al sujeto de color. En Charún-Illescas, el discurso histórico es fracturado de forma deliberada con el propósito de reformularlo desde una perspectiva que pondere elementos de la historia otra. En los tres casos, existe un propósito emancipatorio que puede constituirse en un factor clave de cohesión. De tal forma, parece ser conveniente considerar estas tres obras dentro de un corpus coherente que, a raíz de su manejo deliberado de la oralidad, lo carnavalizado y del elemento político, plantean, en palabras de Antonio Cornejo Polar (1989), un sistema literario propio.

\section{Las representaciones tradicionales de los afrodescendientes: los vestigios del sujeto esclavista en Matalaché (1928)}

La principal novela de Enrique López Albújar, Matalaché (1928), propone una serie de elementos que, de alguna forma, son una reiteración del imaginario estético-político que predominó en las producciones discursivas decimonónicas. La descripción del sujeto afrodescendiente que plantea esta obra se enfoca en su sexualidad como un aspecto esencial de su identidad. El sexo, como rasgo distintivo del sujeto de color, aparece representado constantemente, aunque varía según el género de los personajes. Para el caso de los personajes femeninos, la sexualidad es configurada como una potencia exacerbada e incontenible que aflora, casi de forma espontánea, en cada uno de sus gestos: de algún modo, se asienta en su piel. En el universo de la novela, el rechazo del varón afrodescendiente o su capacidad para contener sus deseos son desestimados en su representación, debido a que nunca es visto, por lo personajes blancos, como una amenaza para sus mujeres. Dentro de la realidad que imagina la novela, una atracción de ese tipo resulta impensable.

Según Marcel Velázquez (2005), la ambivalencia, asentada en la variable de género que determina el trato de los sujetos de color, es una de las claves para comprender de qué manera el siglo XIX convivió con los sujetos afroperuanos. Como señala el estudioso, esta relación determinó un esquema narrativo y una 
Negritud, oralidad y carnaval en la narrativa afrodescendiente peruana del siglo XX (Gálvez Ronceros, Martínez y Charún-Illescas): hacia la conformación de un corpus autónomo

tabla de valores que se mantuvo vigente, incluso, en las primeras décadas del siglo XX (p. 37). Por ello, no resulta extraño que la novela de López Albújar haya interiorizado, en cierto sentido, este imaginario y lo reproduzca en la lógica de su trama narrativa. Si se observa con detenimiento, en el impensable deseo de la mujer blanca por el sujeto afro se erige el quid de la novela. En efecto, sin este tabú Matalaché perdería buena parte de su tensión narrativa y su carga dramática se vería mermada drásticamente.

No obstante, sería errado considerar que esta novela reproduce de forma literal el esquema ideológico del sujeto esclavista, aunque conserve algunos de sus términos. La sexualidad que aparece remarcada en la novela de López Albújar produce simplemente el deseo por la mujer, pero el otro polo - el rechazo y la percepción del negro como peligro para la mujer blanca- es inexistente. Como ya se ha señalado, dicha reformulación tiene que ver con lo impensable de esta unión en la economía ideológica de la novela. En algunos pasajes se puede observar cómo, en los términos de su potencia sexual, se juega la identidad del sujeto afro y de qué forma es inexistente esa contención o esa prevención sobre el varón ya que simplemente su campo de acción se reduce a individuos de su misma raza. La "tentación" de la mujer blanca, por ende, simplemente no es una posibilidad en el mundo representado en la novela. Así, en la novela se afirma que "es fama que entre sus esclavos tiene usted uno para eso del juicio que ni mandado a hacer. Un garañón capaz de apechugar con todas las criadas de la ciudad en una noche" (López Albújar, 1973, p. 13). Queda claro, entonces, puesto que lo negro se define por su potencia sexual que linda con lo animal, con lo salvaje y, como corolario, con la naturaleza, que Matalaché no es un hombre instruido ni sensible, es un garañón. Remarquemos que estamos siempre en la perspectiva de la clase dominante (la cita es parte del diálogo inicial entre Baltasar y Juan Francisco).

El otro aspecto, el deseo que provoca la mujer afro en sus amos, está ya perfilado desde el inicio de la novela. En efecto, el suceso inicial, que da inicio a la narración, es la visita de Baltasar Rejón de Meneses, quien tiene como propósito amancebar a Rita, su criada mulata, con Matalaché, a raíz de la insistencia de la señora de Rejón. La esposa de Baltasar ve a la esclava como una tentación, un 
peligro para la estabilidad de su matrimonio y, tal vez, para la futura repartición del legado familiar: "- Ciertamente, pero es que nunca faltan tentaciones hasta en la propia casa. / — ¡Ah! ¡Esas teníamos! Luego hace bien su esposa en quitárselas de encima. No puede ser más loable su propósito" (López Albújar, 1973, p. 14). Sin lugar a dudas, se observa cómo el aspecto sexual, su potencia, es determinante en la configuración identitaria de los sujetos afrodescendientes, desde el punto de vista de la clase hegemónica en la novela. Así, en el mundo posible que configura esta novela, los únicos que tienen voz — con excepción de Matalaché que, desde su posición de mulato instruido, cuestionará esta identificación, pero de manera ambivalente-, son los sujetos blancos. En este caso, voz y agencia se identifican: habla y poder serán los pilares de una narrativa que reflexiona a partir de las ruinas de una serie de imágenes que, para su época, habían perdido gran parte de su fuerza persuasiva.

\section{Oralidad y elementos del carnaval en Monólogo desde las tinieblas (1975)}

A diferencia de la obra de López Albújar, la narrativa negrista de Antonio Gálvez Ronceros (Orihuela, 2009) acometió de una forma diametralmente distinta la representación del sujeto afrodescendiente. Desde su primera incursión en la narrativa peruana, con su libro de relatos Los ermitaños, Gálvez Ronceros (1962) se propuso no centrarse solo en la representación de los espacios y los sujetos de la zona rural, sino formular un tipo de aproximación que pusiera en primer plano el rescate de la oralidad de esos hablantes. Esta propuesta estética únicamente se esboza en ese primer libro. Los relatos que componen dicho conjunto se centran en la representación de los sujetos mestizos de la costa peruana. No obstante, la campiña, escenario crucial en el segundo libro de Gálvez Ronceros, ya constituye un espacio relevante para la sucesión de las anécdotas. Entre los cuentos de esa ópera prima destaca "Joche", uno de los más sobresalientes de la narrativa peruana del siglo XX. En este relato, la trama se enfoca en describir las desdichas de unos niños que se ven enfrentados a la temprana muerte de uno de sus compañeros. Estos personajes afrontan su existencia desde una posición de extrema marginalidad. De alguna manera, el ser niños entre los desdichados los convierte en seres doblemente desamparados (Mudarra, 2013). 
Negritud, oralidad y carnaval en la narrativa afrodescendiente peruana del siglo XX (Gálvez Ronceros, Martínez y Charún-Illescas): hacia la conformación de un corpus autónomo

En Monólogo desde las tinieblas (1975) ${ }^{1}$, considerado por algunos críticos como su mejor libro (Cuba, 1999; García Miranda, 2009; Solís, 2013), Antonio Gálvez Ronceros esboza uno de los acercamientos más logrados hacia la cosmovisión de las poblaciones de color asentadas en la costa peruana. Este libro, a diferencia de sus antecesores, propone una representación del habla oral negra. Como sostiene María del Carmen Cuba (1999), el empleo del habla constituye un gesto político que resulta clave al evaluar esta obra. Al respecto, Carlos García Miranda (2009), en su ensayo Utopía negra. Representación, escritura/oralidade identidad cultural en la narrativa negrista de Antonio Gálvez Ronceros, sostiene que en Monólogo el autor asume la función de un intermediario cultural cuyo propósito es proponer un punto de contacto cultural que permita un reconocimiento de las poblaciones de color por parte del Estado (2009, p. 57). La lectura de este crítico se basa en el análisis propuesto por Carlos Orihuela (2009), quien considera que la escritura de Gálvez Ronceros en este libro constituye un tipo de literatura negrista, en alusión al indigenismo literario escrito por narradores noindios. Así, para estos críticos, existe una distancia entre el referente y el autor, que recurre, por ello, al empleo de la representación del habla de los personajes de color para intentar suplir esa fractura.

Como se aprecia, aunque apunta sus limitaciones, esta perspectiva crítica valora el potencial político de la oralidad en la obra de Antonio Gálvez Ronceros. Cabe acotar que la palabra hablada posee ciertas características distintivas que no coinciden con la escritura. Como ha señalado Walter Ong (2009), en su clásico libro Oralidad y escritura, el lenguaje es ontológicamente oral. La escritura es, por el contrario, una tecnología que, si bien ha sido interiorizada por la civilización, no forma parte de su organismo ni de su mente, sino después de que el individuo ha sido permeado por la cultura. Esto, además, sostiene Ong, implica que la oralidad posee una serie de pautas de funcionamiento que no pueden ser replicadas, sin menoscabo de su eficiencia, por la escritura, y viceversa. Sobre este punto, Gonzalo Espino (2010) agrega que las culturas orales recurren, para su producción artística por medio de la palabra, a la memoria colectiva como un mecanismo necesario para procesar los saberes acumulados y actualizarlo según 
su circunstancia. Por lo tanto, la operación de representar la oralidad por medio de la escritura constituye una práctica, por lo menos, curiosa o extraña que, por ello, no puede ser desestimada al momento comprender este libro.

Víctor Quiroz (2013) ha propuesto una lectura de Monólogo sobre la base de la teoría bajtiniana del carnaval. Para este autor existen claras muestras del empleo de las figuras del universo carnavalesco propuesto por el teórico ruso en el segundo libro de Gálvez Ronceros. La tesis que defiende Quiroz (2013) sostiene que en Monólogo existe una tensión entre una mirada colonialista que se superpone a la conciencia de algunos personajes y una serie de imágenes del carnaval que desmontan dicho mecanismo de control. Para este crítico, es esencial reconocer cómo los destronamientos y las prácticas del carnaval descritas por Bajtín son fundamentales para la crítica ideológica que propone el conjunto de relatos de Gálvez Ronceros. Uno de los análisis más sugestivos que plantea es aquel dedicado al cuento "Rezador". En este relato existen dos momentos lingüísticamente diferenciados. En el primero, se emplea un registro estándar del español, de fácil comprensión para el lector. En cambio, en el segundo se recurre a una fonetización de la escritura, que, en algunos casos, puede constituir una dificultad para quien se acerque a la lectura. La trama de este relato narra la búsqueda de un "rezador" por parte de un individuo presumiblemente occidental. Luego, se observa directamente la sesión de oración del sujeto afrodescendiente. Para Quiroz (2013), es fundamental la manera en que el lenguaje empleado por el personaje constituye una transgresión de las formas religiosas cristianas:

Señó, Dio mío, padre e too los hombe sobe la tiera, salva elepiritu dete muchacho quel enemigo ta jalando pa su cueva encandelá..... ¡Záape, gato e miera, ta joriendo aqui!...... Joseiiito, Joseiiito, no te vayas po ese camino, quel enemigo ha llená de flore dengaño, de jruta dengaño, de somba dengaño, que son culeirba y sabandija prieta que no ves poque tusojos no ditinguen cosa dengaño... ;Chó, pollo $e$ miera, ta jore que jore! ¿No dejarezá al muchacho no?... Vengan lo viento e mayo, de too lo mayo quian pasá sobe la tiera, vengan con toa la juerza del tiempo y aireen lo monte, aireen lo campo, aireen lo camino, too lo sitio ponde el enemigo ha deparramá su petilencia... ¡Záafa, perro e miera! tamién quiede joré ¿no?... Rio Portachuelo, rio Cañapay, rio La Calera, rio Guamampali y too susermanos del mundo detengan sussaguas, pónganla duras comuel cielo pone dura la lú de lasetrellas pa que no se derame que e necesadio que se pasme 
Negritud, oralidad y carnaval en la narrativa afrodescendiente peruana del siglo XX

(Gálvez Ronceros, Martínez y Charún-Illescas): hacia la conformación de un corpus autónomo

esa semía malina quel enemigo ha puesto en el alma dete muchacho y no levante su brote de epina... ;Calla, pato e miera! No puee cerra ese ojete ¿no? Dio too poedoso, creadó de toooa las plantas, hombes y animale, no pedmitas quel enamigo... iQuiten diaqui, animale $e$ miera! Granmmmmputa cadajo... (pp. 30-31, cursivas nuestras)

Como resulta evidente, la ceremonia de claro carácter religioso es interrumpida abruptamente por un lenguaje soez, que transgrede de modo violento las formas de origen cristiano. A la veneración y el respeto que exigen un ritual de curación, se le oponen las lisuras dirigidas contra los animales. La oralidad, ya de por sí problemática en la representación de un relato en la época en que se publica, adquiere un carácter cuestionador también de los hábitos sagrados. En tal sentido, puede hablarse, siguiendo a Bajtín, acerca de que los códigos del carnaval operan en este relato. Como sostiene el teórico ruso,

[...] el carnaval es un espectáculo sin escenario ni división en actores y espectadores. En el carnaval, todos participan, todo el mundo comulga en la acción. El carnaval no se contempla ni tampoco se representa, sino que se vive en él según sus leyes mientras estas permanecen actuales, es decir, se vive la vida carnavalesca. Esta es una vida desviada de su curso normal; es, en cierta medida, la "vida al revés", el "mundo al revés".

Las leyes, prohibiciones y limitaciones que determinan el curso y el orden de la vida normal, o sea, de la vida no carnavalesca, se cancelan durante el carnaval [...]. En el carnaval se establece, en una forma sensorialmente concreta y vivida entre realidad y juego, un nuevo modo de relaciones entre toda la gente, el cual se opone a las relaciones jerárquicas y predominantes de la vida cotidiana. (Bajtín, 2012, pp. 242-243)

Para Bajtín, como se aprecia en la cita, el carnaval constituye un acontecimiento con pautas específicas. Se puede decir que se trata casi de un lenguaje organizado como un sistema de significaciones. El carnaval provoca que el tiempo y el espacio se articulen a partir de la fiesta popular (Bajtín, 1988, p. 23). En este nuevo contexto es posible que se establezcan relaciones que en la vida cotidiana serían imposibles. Todo ello provoca que las jerarquías establecidas durante el tiempo de la vida cotidiana, aquellas que sofocan las posibles interacciones entre ámbitos sociales disímiles, queden inoperantes. Así, en el relato de Gálvez Ronceros se aprecia cómo la transgresión del lenguaje religioso posee una resonancia política y social. Entonces, se puede decir que la 
oralidad y el imaginario del carnaval constituyen dos elementos que confluyen y se complementan en la narrativa de los relatos de Monólogo. En dicho sentido, se puede afirmar que el carácter emancipatorio de la mayoría de estos relatos se articula a partir de la combinación de la voz y del carnaval.

En otros cuentos de Monólogo se reincide en esta práctica, la combinación de la representación de la voz del sujeto afrodescendiente y el recurso a imágenes del carnaval. Como se ha mencionado, el carácter político de la representación del habla es una característica constitutiva de los relatos del segundo libro de Antonio Gálvez Ronceros. Al respecto, la propuesta de Víctor Vich \& Virginia Zavala (2004) es de suma relevancia. Para estos autores, se trata de reconocer que los mensajes orales se encuentran inscritos en coyunturas específicas donde actúan fuerzas, algunas veces, contradictorias. La dinámica de los mensajes se halla enmarcada e inscrita en diversas redes de poder que dependen de cada contexto para su adecuada decodificación (Vich \& Zavala, 2004, p. 18). Jorge Terán también ha problematizado el espacio de la palabra como producto de una negociación entre el investigador y quien proporciona su testimonio. Para este autor, el objetivo que deben perseguir los análisis de las producciones orales es la observación precisa de las fuerzas que entran en litigio cada vez que alguien habla (Terán, 2008, p. 53).

Un cuento de Monólogo que representa las tensiones entre la palabra oral y el poder es "El carnet". La trama del mismo se centra en la confrontación entre un oficial, representante de la autoridad estatal, y un agricultor de color. El encuentro de ambos personajes es, desde el inicio del relato, conflictivo:

Llevando un atado de paja de frejol, un negro muy viejo atravesaba la solitaria placita de la hacienda. Al pasar frente a la comisaría un guardia que se aburría en el umbral le dijo:

- iAlto!

-Aquí toy, señó.

- Su carnet.

- Señó, cainé tengo, pero ta pa llená.

-Y por qué no lo ha hecho llenar.

- Güeno... Resuta que yo tabajo too lo día e la semana. Y ahí ta don Erique Cabreira, que mi bueye se caen de hambe, mueto, jalando agua 
hata lo día domingo pa la casacienda. Po ese motivo no pueiro i al pueblo. Dicen que hay que i a tomase una fotorgafía en un apadato, quiuno se pone derante, y atrá una con capa nera dice: “iEtric! Ya ta lito". Y dicen quese apadato queda en una calle que se llama Derecha, y como quieda que yo no vual pueblo dede quesa calle era torcira... (pp. 61-62)

Es importante constatar que la diferencia entre ambos personajes no solo está definida por su relación con el poder, ya que, si únicamente radicara en ese aspecto, es probable que el carácter humorístico del relato se perdiera. Ambos personajes se distinguen, fundamentalmente, por el registro lingüístico que emplean en su comunicación hacia el otro. Para el lector, resulta evidente que se trata de personajes inscritos en redes culturales disímiles. Ello quiere decir que a la diferencia de rangos se le une otra que incide en el horizonte cultural que define la posición ideológica y cognitiva de ambos personajes. Esto último viene a colación a raíz de las ideas de Walter Ong. Como se indicó, la escritura conforma la mente humana de una forma diferente. Es decir, el aprendizaje de la escritura supone la modificación del razonamiento y de la cognición de los individuos (Ong, 2009, p. 67). Como señala Ong, no se trata de atribuir una valoración ética al asunto de cuál conformación es mejor, sino de comprender cuáles son los cambios que sufre la mente al entrar en contacto con la escritura. Este teórico postula la existencia de comunidades definidas por una oralidad primaria, es decir, sociedades que nunca han tenido contacto con la escritura (Ong, 2009, p. 34).

Como se aprecia en el relato, en la manera de preguntar y responder se manifiestan dos formas de concebir la realidad y la existencia. Como señala Ong, para aquellos hablantes que únicamente manejan el código oral es imprescindible remitir siempre al referente. Este hecho es patente en la parte final del relato. Ante la pregunta por el lugar donde vive, el protagonista responde: "Ya. Uté ta aquí, ¿no? ¿Uté ve esa planta de epigua que ta allá ponde viene volando esa mancha e pericos? Esa planta e de...” (Ong, 2009, p. 62). La representación de la oralidad en Monólogo, entonces, no se reduce únicamente a la fonetización del registro escrito. También, supone el intento de aproximarse a la forma de concebir la realidad, es decir, constituye un esfuerzo por representar la cognición. Este 
esfuerzo por brindar una representación del sujeto de color que no se reduzca solo a su descripción externa se percibe en otros relatos como "Octubre" o "Miera", texto que aparece al inicio del libro en todas sus ediciones. En este relato, el protagonista se caracteriza por proferir palabras soeces: “-Ponle ahí, Patora dijo don Andrés - , que su boca esuna miera, que su diente esota miera, su palaibra un montón de miera... Miera esa mula que monta. Miera su epuela. Miera su rebenque. Miera el sombreiro con quianda. Miera esa cotumbe e miera diandá mirando tabajo ajeno... Léemela, Patora, a ve qué fartra" (p. 10). El remate final incide en el rol trasgresor de la oralidad al mostrar la incompatibilidad entre el registro escrito y el oral: “-Oye, Patora — dijo finalmente—, quítale un poco e miera a ese papé" (p. 10).

En resumen, es válido sostener que el rol que cumplen la representación de la oralidad y el imaginario carnavalesco posee una finalidad transgresora con hondas resonancias políticas. Este libro inaugura un tipo de representación divergente respecto a la canónica, como en el caso de Enrique López Albújar, del sujeto afroperuano. En esta línea surgirán otras obras que, a través de estrategias diversas, manifiestan una orientación de corte político, en vista de que problematizan las instancias discursivas hegemónicas y los estereotipos instaurados en la tradición literaria peruana.

\section{Voz, testimonio y cuerpo en Canto de sirena (1977)}

La primera novela de Gregorio Martínez, Canto de sirena (1977), constituye un hito en la representación del sujeto afroperuano. A raíz de su composición y de su forma, la propuesta de Martínez problematiza la idea misma de autor y el proceso de producción literaria. Como ha sido señalado por la crítica, su propia inscripción en el género novelístico resulta un problema (Carazas, 1998; Macedo, 2008). Como es evidente tras su lectura, la condición textual del protagonista excede la tipología usual que suele emplearse para el comentario de las obras literarias. Por lo general, un personaje puede inscribirse en el lugar central de la narración, en tanto productor de enunciados (es decir, se coloca en el origen de la enunciación o, tradicionalmente, ocupa la posición de narrador) o como sujeto central y reiterado de esos enunciados (o, en términos convencionales, funge de 
protagonista). Por el contrario, en la novela de Martínez, el personaje central, que es al mismo tiempo quien narra su propia vida - transgrediendo la secuencialidad cronológica y la necesidad lógica que, tradicionalmente, había caracterizado a estos relatos en el siglo XIX (Levin, 1974, p. 49)—, es también un "informante" y, por lo menos en parte, el autor de la obra (Carazas, 1998, p. 17).

Por ello, la obra de Martínez es radicalmente divergente a buena parte de la narrativa peruana. Esta singularidad es resultado de la apropiación de los recursos de la entrevista etnográfica, practicada en el ámbito de las ciencias sociales (Carazas, 1998, p. 23). El empleo de esta metodología en la producción de la novela constituye uno de los pilares de su propuesta narrativa. En otras palabras, por su estructura, estilo y producción, esta obra oscila entre el testimonio, la novela y la novela testimonial. Para Milagros Carazas, la mejor opción frente a este dilema es apostar por el carácter literario de la obra (1998, p. 12). En su opinión, en la novela de Martínez el elemento literario prevalece sobre los recursos provenientes de las ciencias sociales. Por ello, se debe pensar Canto de sirena como una obra literaria que recurre a procedimientos y recursos de las disciplinas de raigambre sociológica para reconstruir, desde la literatura, una concepción de mundo y producir una obra artística (1998, p. 15).

No obstante, la presencia de la memoria como elemento esencial de la narración del protagonista-enunciador(-autor oral) de la novela, Candelario Navarro, Candico, es un elemento que no se puede soslayar. Tal como sostiene Gloria Macedo (2008), es necesario comprender el papel productivo de la memoria en la narración, en tanto que es la instancia principal que propicia el desenvolvimiento de la trama. En otros términos, la composición compleja del narrador-protagonista se relaciona con el papel central que posee la memoria en la narración. Según Macedo, la memoria es el núcleo central de la novela, que, si en efecto es un canto, como anuncia uno de los epígrafes iniciales ${ }^{2}$, se nutre de la experiencia vital del protagonista de forma permanente para ejecutar su partitura (Macedo, 2008, p. 56). No obstante, contra lo que podría pensarse, no se trata solo de la memoria individual, sino, como sostiene Macedo, de la memoria de todo un pueblo, Coyungo (Macedo, 2008, p. 73). Esto significa que en la novela opera una 
memoria colectiva de forma transversal a lo largo del relato. Desde la "noticia" que inicia la novela, este hecho es patente:

Esta dichosa villa que dicen que fue lugar de escarnio tenía y yo lo vide y me consta uno de los mejores vinos que no es exageración si afirmo $\mathrm{y}$ juro que era un vino clarísimo suave y fragancioso de uvas mollares de sombra y bajera ásperas más bien y otras asoleadas y dulces casi como la miel silvestre porque las unas eran carnudas blanquísimas $\mathrm{y}$ tersas casi del tamaño de una ciruela y las segundas apretadas y dulzaínas pero con mucho zumo tanto como las primeras de manera que así se conseguía un vino de bien logrado cuerpo a pedido de boca y paladar. Tampoco faltaba en esta dichosa villa que dicen que fue de castigo y suplicio el agua barrial y de sabor limpio que era el mayor placer abrevarla en los vertederos que como cosa natural caían de las peñas y barrancos donde se veía verdear con primorosa frescura la flor de agua y el culantrillo. (Macedo, p. 13, cursivas nuestras)

Como se aprecia en la cita, desde un inicio el proyecto narrativo de Canto de sirena articula la experiencia individual y la historia colectiva. Una de las directrices de la narración es, por consiguiente, la compleja relación que se establece entre ambas instancias. El relato del protagonista es el soporte de la historia de todo un pueblo. Esto quiere decir que en sus memorias se desliza reiteradamente la historia de toda la comunidad, los avatares que han definido el devenir de su colectividad de origen. Es fundamental, entonces, comprender la relevancia que posee el uso de la oralidad en el discurso novelístico de Canto de sirena.

Si bien la representación del habla del sujeto afroperuano no es tan radical como en el caso de Gálvez Ronceros, no se debe soslayar la importancia de este elemento en la construcción de la novela. En realidad, si se piensa con calma, al igual que en el caso del autor de Monólogo, la identidad del narrador arraiga, precisamente, en su forma de hablar. Su naturaleza, para el lector, es, en esencia, lingüística. No obstante, se trata de establecer que el registro oral, de forma inmediata, remite a ese hablante hacia la comunidad a la que pertenece. Se establece, así, una suerte de vínculo indestructible entre el narrador-protagonista y la comunidad de la que procede. De alguna manera, la potencia de la narración descansa en esa relación, que es aprovechada de forma continua. No se trata solo de la historia como proceso, es decir, como transcurrir de los hechos en el tiempo, sino, también, de los saberes de la comunidad que, a través de su discurso, el narrador conserva: 
Los cerros de esta banda son grises, de una arena gruesa, sin una sola planta de nada. Los de la otra banda son blancos, con grandes cuajarones de argamasa amarillenta, ocre, y una vegetación aislada, enormes manchas de un verde plomizo, árido, formadas por toñuces y guarangos rastreros que no crecen para arriba, como manda natura, sino que gatean y se extienden igual que un camotal, buscando la humedad del sereno que cuaja en el suelo durante la noche. En esta banda solo hay arena y sequedad, detrás de los cerros se extiende el pleno desierto, las pampas de Mocos y Arrancatrapo. (p. 91)

Nos pareció raro, a nosotros, estábamos huaqueando por cuenta de don Usebio Carbajal, no para estudio ni para museo sino para don Usebio que era el dueño de esas tierras, estábamos en Yauca, de Chaviña más al sur, como quien se va para Chala, ahí justo, estábamos nosotros, la cuadrilla, huaqueando para Usebio Carbajal, y digo que nos pareció raro, a nosotros, porque la huaca era como un pozo, no parecía tumba sino un pozo. (p. 108)

El paisaje, los saberes y los acontecimientos de la comunidad son transmitidos a las generaciones siguientes por medio de la palabra del narrador. Esto permite comprender la envergadura que el proyecto narrativo de Martínez adquiere en esta novela. No se puede comprender la forma cómo es concebido el lenguaje en su obra sin admitir que el rol de la oralidad es un factor determinante que, de alguna manera, modifica el estatuto del lenguaje en la obra. Como ha señalado Valentín Volóshinov, la palabra, cualquier palabra, debe ser vista como una realidad dialéctica, ya que siempre, en el fondo, es el producto de la interacción entre una "palabra propia" y "una palabra ajena" (2009, p. 193). Dicho de otra forma, el carácter social del lenguaje implica que las palabras usadas por cualquier hablante son, al mismo tiempo, de uso compartido, lo que provoca que, de alguna manera, queden impregnadas de ese empleo plural. La palabra es múltiple. Cada palabra queda marcada por los hablantes que han hecho uso de ellas.

Mijaíl Bajtín reelaboró la noción de "palabra ajena" propuesta por su compatriota desde la óptica del diálogo. Para el estudioso ruso, el lenguaje es, por naturaleza, dialógico, es decir que, cuando se emplea, la mayoría de veces surge como respuesta a una palabra previa (Bajtín, 1991, p. 68). En tal sentido, toda palabra se haya inscrita, en diversas formas y grados, en un diálogo anterior. Esto quiere decir que las palabras no se dirigen de forma unívoca a los objetos 
que refieren, sino muy pocas veces. La mayor parte de nuestro uso diario del lenguaje está determinado por su carácter dialógico (Bajtín, 1991, p. 74). Desde una perspectiva semejante, Pierre Bourdieu considera que el carácter social del lenguaje, que se presenta, por lo general, como un rasgo esencial de su naturaleza, en realidad no puede ser puesto en ejecución por todos los hablantes, ya que existe una serie de factores que establecen diferencias entre ellos y, por lo tanto, surge una discriminación en su mismo empleo (Bourdieu, 1985, p. 23). Por tal razón, el uso del lenguaje hablado constituye una pieza capital que enarbola Canto de sirena, ya que, al apelar a este registro, determina, en un solo proyecto, un tipo de relación que reconcilia lo individual con lo colectivo.

Asimismo, aunque es evidente que la fonetización de la escritura no es el recurso principal para representar la voz del campesino de color en la novela de Martínez, se emplean otros procedimientos textuales para fijar en la escritura la palabra viva del informante Candico. Por ejemplo, es común el uso de un lenguaje que recurre, sin amaneramientos y, acaso, de forma brusca, a la coprolalia o el empleo de una sintaxis desbordada, que reemplaza, sin aspavientos, el punto por la coma:

Es que el año 23, estoy viendo, me volví malo, me contagié de los blancos la soberbia y altanería, agarré de ellos el desplante, el hambre de acaparar todo sin ponerme a pensar en la necesidad de otros, me acuerdo que como me iba de viaje, a traerme una muchacha de Estudiante que ya la tenía bien convecida, hice cortar todas las naranjas del árbol que estaba frente a mi casa, las hice cortar todas, y luego todavía me puse a buscar entre las hojas, me nacía ese capricho de joder a quienes habían estado pensando aprovecharse de mi ausencia para cosechar ellos, ahora me voy tranquilo, dije, viendo el follaje limpio de naranjas, me voy sin la zozobra de que me van a joder, si se les antoja robar, no importa, que roben hojas, les dejo el árbol enterito, que se harten si quieren que se hostiguen de verdura, dulce, amargo, ¿qué gusto tendrá?, el olor sí es rico, pensaba [...]. (p. 104)

El objetivo de estrategias de este tipo es situar el discurso narrativo en la voz del hablante. Al ubicar el vínculo entre la comunidad y el individuo en la enunciación del narrador-protagonista, Martínez consigue definir un proyecto narrativo que, en principio, puede servir como una plataforma política, en tanto recupera la voz de una comunidad específica y, por medio de un razonamiento sinecdótico, de toda la población afroperuana. 
Negritud, oralidad y carnaval en la narrativa afrodescendiente peruana del siglo XX

(Gálvez Ronceros, Martínez y Charún-Illescas): hacia la conformación de un corpus autónomo

Sin embargo, la propuesta escritural de Martínez en Canto de sirena recupera también el humor carnavalesco propio de las culturas populares (Bajtín, 1988). Como se sabe, la risa constituye una pieza esencial en las tradiciones populares. Según Bajtín,

[...] la época de Rabelais, Cervantes y Shakespeare, representa un cambio capital en la historia de la risa. Las fronteras que dividen el siglo XVI y siguientes de la época renacentista son especialmente claras en lo que respecta a la opinión que tienen sobre la misma. (Bajtín, 1988, p. 65)

Durante el Renacimiento, según el teórico ruso, la risa posee un valor trascendental en la cosmovisión de los hombres de esa época: la risa

[...] es un punto de vista particular y universal sobre el mundo, que percibe a este en forma diferente, pero no menos importante (tal vez más) que el punto de vista serio: solo la risa, en efecto, puede captar ciertos aspectos excepcionales del mundo. (Bajtín, 1988, p. 65)

El aprecio por la risa cambiará en los siglos siguientes, cuando solo pueda abarcar aspectos parciales de la existencia:

[...] no es posible expresar en el lenguaje de la risa la verdad primordial sobre el mundo y el hombre; solo el tono serio es de rigor; de allí que la risa ocupe en la literatura un rango inferior, como un género menor, que describe la vida de individuos aislados y de los bajos fondos de la sociedad. (Bajtín, 1988, p. 65)

En Canto de sirena, no obstante, la risa carnavalesca se hace presente en diferentes pasajes y, prácticamente, no existe ningún aspecto que escape a su potencia desacralizadora, ni siquiera el narrador-protagonista. Así, por ejemplo, cuando se presenta, en las primeras páginas de la novela, el propio narrador se "destrona" (Bajtín, 2012, p. 267) por medio de la animalización:

El gusto de andar oliéndoles el trasero a las mujeres como el toro a la vaca todavía me dura, pero antes de mi regreso a Coyungo era más encendido y casi no tenía atajadero, no respetaba amenazas, parejo, como un toro que ha estado amarrado años y que de repente rompe el cabestro, así iba yo haciendo destrozos, rompiendo quinchas, tumbando trancas, sin respetar a quienes salían a atajarme con palos, con bala $[\ldots]$.. (p. 18)

Este procedimiento resulta común en buena parte del libro y se aprecia, en especial, en la forma en que parodia los discursos científicos y religiosos de la 
época. Conviene detenerse en la manera cómo la historia sagrada es cuestionada en la voz del narrador:

Ahí están los gentiles, ellos tenían a Wiracocha, igual como nosotros de ahora tenemos al Padre Eterno, a Jesucristo y a la mamá de Jesucristo, que le decimos la Virgen, aunque si nos apegamos a la estricta verdad no es Virgen nada, ¿acaso ella no ha parido?, ha parido, entonces si ha parido ya no es Virgen, nadie pare del viento, ni la gallina [...]. (p. 44)

La oralidad y el trasfondo carnavalesco que predominan en la narración son determinantes para que aparezcan resquicios, como en el fragmento citado, en los que el protagonista pueda cuestionar las verdades oficiales. Por ello, puede afirmarse que es la conjunción entre memoria colectiva, oralidad y humor carnavalizado lo que sirve de asidero para plantear un discurso que confronte los discursos que legitiman la realidad y el poder.

En síntesis, en Canto de sirena de Gregorio Martínez, al igual que en Monólogo desde las tinieblas de Gálvez Ronceros, se puede apreciar que operan la oralidad y algunos elementos del humor carnavalizado como estrategias discursivas que sirven de base para la construcción de una voz que ayuda a cuestionar las instancias discursivas de poder. Por lo tanto, puede afirmarse que estos elementos contribuyen a diseñar una narrativa que cuestiona el orden imperante y que puede haber brotado de un anhelo emancipatorio.

\section{Historia, umbral y cuerpo en Malambo (2001)}

Dentro de la historia de las obras relacionadas con la cultura afroperuana, Malambo (2001), novela de Lucía Charún-Illescas, constituye un hito de suma importancia. Las dos primeras razones para ocupar ese puesto de honor saltan a simple vista. En primer lugar, es una novela escrita por una autora de color. Buena parte de la literatura que ha tenido como objeto de interés el universo cultural del hombre afroperuano ha sido producida por autores que, la mayoría de veces, no pertenecían a esta etnia, incluso en obras donde el nivel de representación es sumamente sofisticado, como sucede con Antonio Gálvez Ronceros y Gregorio Martínez. A este detalle se le suma la variable género. Charún-Illescas es la primera novelista afroperuana de la narrativa del país. No obstante, existen otras razones textuales que justifican la importancia de esta novela para el devenir de la narrativa 
nacional, como la manera en que problematiza la historia oficial, las alusiones al imaginario ancestral de la cultura yoruba, el empleo de recursos procedentes de la novela polifónica y el modo en que incluye en su estructura la variable género.

Entre todos estos méritos, destaca la relación con la historia que la novela consigue esbozar. Como ha señalado M'Bare N'gom (2008), la obra de Charún-Illescas se propone rearticular el discurso histórico desde la perspectiva de los sujetos de color, desde un punto de vista considerado durante muchos años como marginal y carente de valor. En tal sentido, el objetivo central de la novela surge del diálogo entre la versión oficial de la historia y una versión alternativa donde los protagonistas son los sujetos marginales por excelencia de la colonia, los esclavos de color, que se situaban en la última escala social. No obstante, la novela comprende, en esencia, un espacio ficcional en el que, además de incluir elementos de una visión marginal de la historia, se formula una serie de elementos que configuran una utopía. La ficción, dicho de otra manera, no solo confronta versiones de la historia, sino propone una realidad en la que, a pesar de su condición, el curso de la narración depende enteramente de los personajes de color. En otras palabras, el universo ficcional constituye, de alguna manera, una reivindicación histórica. Como sostiene Juan Manuel Olaya,

Charún-Illescas toma este referente histórico [el barrio colonial de Malambo] y, siguiendo esta línea, logra que Malambo se enlace con éxito en el proceso de la literatura afrolatinoamericana, pues la diáspora africana y la esclavitud como temática transversal, en un contexto pluricultural e interétnico, hacen que esta novela se inscriba en el proceso de reescritura de la historia oficial y de la esclavitud africana en el Nuevo Mundo desde la ficción literaria. De ahí que algunos la consideren como "novela histórica". (Olaya Rocha, 2017, s. p.; cursivas nuestras)

Es este proceso de reescritura mencionado por Olaya el que dota a Malambo de su calidad de objeto cultural de resistencia y de reivindicación de los sujetos afroperuanos. En otras palabras, el sentido más poderoso de la novela surge de la tensión con el discurso de la historia oficial. Al respecto, es importante considerar la distinción que Bajtín propone entre cultura oficial y cultura no-oficial. Como sostiene el teórico ruso, la cultura oficial es aquella respaldada por el poder, que establece una serie de jerarquías que se suponen inexorables y eternas, y que 
diseña el territorio social como compartimentos estancos y aislados. Sin embargo, durante la época de carnavales, que eran muy comunes durante la Edad Media y el Renacimiento, se vivía en las plazas y calles la inversión del mundo, es decir, se desataban todas las ataduras sociales y se suspendían, en un tiempo y espacio determinado, las jerarquías que impedían la libre relación entre individuos de diversos estratos (Bajtín, 1988, p. 79). La cultura no-oficial es el resultado del trabajo creador y anónimo del pueblo que, según Bajtín (1988, p. 46), posee un sentido profundo de la historia y la existencia humanas. Entonces, hablar de una historia oficial es, en principio, aceptar que es la versión forjada desde el poder, cuya capacidad de ocultamiento es semejante a su potencia esclarecedora.

En Malambo, la historia es contada pero de forma invertida: son ahora las acciones de los esclavos las que marcan el ritmo de la narración y son los avatares de su existencia los que componen el universo ficcional que propone la novela. Tal vez, por esa razón, sorprenda al lector el desparpajo y las continuas profanaciones que realizan los personajes. Esta característica es evidente en el accionar de personajes como Tomasón Ballumbrosio, el pintor de Malambo, un artista explotado por su amo, que constituye uno de los pilares de la narración. Su manejo de las artes pictóricas, su avanzada edad y su estado de salud, le permiten vivir con cierta libertad de palabra, pensamiento y acción. En una de las escenas más curiosas de la novela, este personaje entrega una representación a pedido que desacraliza una imagen religiosa:

Sostiene el lienzo que le entrega Tomasón y se le salta la sangre al rostro. El motivo es abiertamente obsceno. La Virgen María semidesnuda de la cintura para arriba amamanta al niño Jesús de un pecho y del otro, a San José. (p. 70)

Esta profanación es una muestra de la perspectiva que adopta la narración al momento de relacionarse con la historia. Se trata, así, de un esfuerzo por reformular, cuestionar o transformar la narrativa oficial por medio de diferentes recursos.

Como en los textos analizados previamente, en Malambo también existe una incorporación de la oralidad y del humor carnavalesco, grotesco y corporal. 
Sin embargo, su expresión no resulta tan abrupta ni visual. Existe en CharúnIllescas una marcada contención de estos elementos y un uso que privilegia la eficacia ante todo. En el primer caso, la oralidad se hace presente en algunas narraciones o cantos incluidos en diversos pasajes de la novela. Por ejemplo, cuando recién adopta a Pancha Parra, Tomasón se despierta de improviso diciendo:

_...Ño mono, pasaba cerca a un pozo y oye que alguien se está quejando. Entonces, se acerca y pregunta. — ¿Quieeeén estaaaá alliiií?

—Sooooy yoooo, eel pumaaa Ñooo moonooo ¡Pooor faavooor! Saaáqueeeme dee aquiií.

—Primerooo proométaaameee queee no mee haraá mal.

—Prooometiiido estaaá. (pp. 60-61)

Esta breve fábula sobre el origen de la maldad en la sociedad se incorpora a partir de la memoria del personaje. No obstante, al igual que en el caso de Gregorio Martínez, esta nunca es únicamente individual. Se trata de una memoria que conserva la cultura de la comunidad. En tal sentido, es también una reserva de los valores y saberes ancestrales del grupo social de procedencia. En efecto, son los vestigios de la cultura yoruba los que, en diversos momentos de la narración, se incorporan y actualizan por medio de la inclusión de elementos forjados al calor de los códigos de la oralidad. A lo largo de la novela se presentan fábulas, canciones, refranes y recetas (medicinales en el caso del personaje de Pancha) que contribuyen a reforzar la vigencia de esa tradición cultural, a mostrar que el lugar de origen se desplaza con los personajes mismos, que a pesar de haberse separado de su tierra natal aún conserva el olor de su tierra en el alma.

Asimismo, en la novela se recurre a elementos de la cultura cómico popular por medio de un humor grotesco que encuentra en el cuerpo uno de sus principales puntos de apoyo. Cabe recordar que la corporalidad dentro del imaginario del carnaval posee una condición específica. Como ha señalado Bajtín, la concepción moderna del cuerpo se remonta recién a mediados del siglo XVII. Es decir, la comprensión actual del cuerpo, que lo imagina como una entidad definida y separada de su entorno y de otras naturalezas distintas, adquirió forma a finales del Renacimiento: 
El rasgo característico del nuevo canon [...] es un cuerpo perfectamente acabado, rigurosamente delimitado, cerrado, visto del exterior, sin mezcla individual y expresivo. [...] Asimismo, se cierran todos los orificios que dan acceso al fondo del cuerpo. [...] Esta superficie cerrada y unida del cuerpo adquiere una importancia primordial en la medida en que constituye la frontera de un cuerpo individual cerrado, que no se funde con los otros. (Bajtín, 1988, p. 288)

Sin embargo, durante la Edad Media y el Renacimiento, y especialmente en épocas de carnaval, la imagen del cuerpo es radicalmente diferente. Bajtín entiende el cuerpo desde la lógica del realismo grotesco. Para este autor, es fundamental determinar la manera cómo esta configuración estética define la corporalidad humana:

Lo grotesco se interesa por todo lo que sale, hace brotar, desborda el cuerpo, todo lo que busca escapar de él. Así es como las excrecencias $\mathrm{y}$ ramificaciones adquieren un valor particular; todo lo que, en suma, prolonga el cuerpo, uniéndolo a los otros cuerpos o al mundo no corporal. (Bajtín, 1988, p. 285; cursivas nuestras) ${ }^{3}$

En consecuencia, el cuerpo grotesco, componente esencial del carnaval, resulta una configuración excesiva y desbordada, y es vital para el tipo de humor desacralizador y ambivalente que predomina en épocas de fiestas.

Dentro de la novela Malambo existen varios pasajes en los que la alusión a la corporalidad constituye un elemento cuestionador que suspende momentáneamente las jerarquías. Por ejemplo, en la escena en que se presentan a los esclavos - algunos de los cuales son criollos que, después de haber vivido libres parte de su vida, han sido forzados a volver al dominio del blanco--, uno de ellos realiza un gesto obsceno que desarticula la relación de poder establecida desde un inicio:

- Hombres hechos para el trabajo duro. Están libres de cualquier enfermedad. Mírenlos bien - les comentó, arrancándole el taparrabo. Guararé tomó entre sus manos su verga abultada y brillante de aceite. Les mostró que no tenía los huevos descolgados, potra o enfermedad vergonzosa. Un murmullo de admiración y una que otra risita boba lo rodearon.

Un comprador preguntó en tono zumbón: 
Negritud, oralidad y carnaval en la narrativa afrodescendiente peruana del siglo XX

(Gálvez Ronceros, Martínez y Charún-Illescas): hacia la conformación de un corpus autónomo

— ¿A todos los revisa personalmente? Miren eso, yo pensé que solo lo hacía con las mujeres.

De la Piedra se sintió de mal humor. (p. 95)

El cuerpo, como una presencia indómita, interrumpe, por un instante, el flujo del poder e invierte su funcionamiento: el esclavo revisado (tocado) por el vendedor se convierte en el "dueño" de la situación al cuestionarse la sexualidad del segundo. En otras palabras, la relación de sometimiento se reformula en una relación sexual imaginaria donde los papeles se invierten. Por ello, es posible afirmar que la corporalidad desbordada, que remite al imaginario del cuerpo grotesco del carnaval, es uno de los pilares de la narración.

Asimismo, a veces, también se presenta como un cuerpo enfermo, en descomposición, como en el caso de Altagracia Maravillas que sufre un accidente que lesiona uno de sus brazos. La primera parte de la novela presenta el deterioro de su brazo dañado. Incluso, en algunos pasajes, se sugiere que puede perder la extremidad por la falta de cuidados médicos. Sin embargo, lo interesante de este motivo radica en la manera cómo Charún-Illescas aprovecha para insertar el rol de la mujer como guardiana de la cultura originaria. En efecto, las secuelas del accidente de Altagracia parecen ser definitivas hasta que Pancha Parra, que desde un inicio se ha presentado como conocedora del saber ancestral del cuidado a través de las plantas ("Pero ¿yerbas?, eso sí conozco. Muchas yerbas” [p. 35]). Bajo el amparo de Pancha, el personaje de Altagracia consigue ver algunas mejoras en su salud:

Se sentó en el suelo y fue deshaciendo el amarre de rapos, yerbas sobre ungüentos y emplastos y más yerbas y hojas maceradas que le recetara Pancha.

A las doce del mediodía, los gallos cantaron. La piel mostraba moretones, estaba reseca y escamosa, pero la hinchazón había bajado y pudo accionar el brazo. Lo levantó a la altura de su rostro. Obedeció a su gusto, estirándose o formando un puño. Lo bajó y se pellizcó incrédula de sentir otra vez el cosquilleo de los vellos en el sobaco, el redondeo del hombro, la punta del codo áspero y las uñas rotas. (p. 190)

En este caso, la remisión al cuerpo dañado es también una forma de reconocer el rol de la mujer como resguardo de los saberes de las culturas 
originarias. De alguna manera, en la utopía que propone Charún-Illescas, varones y mujeres afrodescendientes consiguen establecer vínculos de afecto en condiciones semejantes, sin menoscabo de su autonomía.

En resumen, la novela de Charún-Illescas, Malambo, de una manera particular, recupera los recursos de la oralidad y el universo de la cultura del carnaval. A diferencia de los autores estudiados anteriormente, prevalece en la escritura de esta autora una contención y un manejo más sofisticado de tales elementos. En este caso, si bien poseen aún su carácter cuestionador, su empleo responde a objetivos más específicos dentro del funcionamiento de la novela. Asimismo, es evidente que el cuerpo y las condiciones de autonomía de los sujetos femeninos son también variables a considerar en el imaginario de esta obra.

\section{Conclusiones finales}

Como se ha mostrado, las novelas de Gálvez Ronceros, Martínez y Charún-Illescas comparten el uso de dos recursos esenciales en la configuración de sus universos ficcionales. En primer lugar, la oralidad se instaura como uno de los pilares de la arquitectura de estas obras. Si bien la manera como se usa puede variar según el enfoque de cada autor, es innegable que el aprovechamiento de la tradición oral constituye un rasgo decisivo en la conformación de los imaginarios que proponen los textos estudiados. En segundo lugar, diversos elementos de la cultura cómico popular son empleados de forma particular en estas narraciones. Aunque es evidente que los usos, funciones y proporciones varían, es crucial identificar este elemento como un componente esencial de estas ficciones. Por ello, puede afirmarse que Monólogo desde las tinieblas, Canto de sirena y Malambo incorporan, en diversos grados, elementos semejantes, lo que permite afirmar que constituyen un corpus autónomo. Es decir, son parte de una tradición que se ha definido, en gran medida, durante el siglo XX, pero se encuentra todavía en pleno desarrollo.

\section{Notas}

1 Este libro ha tenido cuatro ediciones $(1975,1986,1999$ y 2017). En la tercera se agregaron cinco relatos nuevos que, si bien con una temática y una apuesta estilística similar a los originales, poseen una extensión mayor y evidencian una mayor presencia del narrador. En tal sentido, modificaron el conjunto. Por ello, para 
esbozar la interpretación propuesta se trabajará con la edición príncipe. Todas las citas corresponden a esta edición, por lo que únicamente se consignará el número de página correspondiente.

2 «Esto, no es una historia, es un canto: / en octubre, mes de los zorros, cantan / las sirenas» (p. 11). Todas las referencias corresponden a la edición citada en la bibliografía, por lo que únicamente se consignará el número de página correspondiente.

3 En el caso de Bajtín, esta comprensión del cuerpo posee un fundamento ontológico que parte de la interacción entre el yo y el otro (cfr. Bajtín, 2015).

\section{Referencias bibliográficas}

Bajtín, M. (1988). La cultura popular en la Edad Media y el Renacimiento. El contexto de François Rabelais. Madrid: Alianza Editorial.

Bajtín, M. (1991). Teoría y estética de la novela. Madrid: Taurus.

Bajtín, M. (2012). Problemas de la poética de Dostoievski. Ciudad de México: Fondo de Cultura Económica.

Bajtín, M. (2015). Yo también soy. (Fragmentos sobre el otro). Buenos Aires: Ediciones Godot.

Bergson, H. (2016). La risa. Ensayo sobre la significación de lo cómico. Madrid: Alianza Editorial.

Bourdieu, P. (1985). ¿Qué significa hablar? Economía de los intercambios lingüísticos. Madrid: Akal.

Carazas, M. (1998). La orgía lingüística y Gregorio Martínez. Un estudio sobre Canto de sirena. Lima: Línea \& Punto.

Charún-Illescas, L. (2001). Malambo. Lima: Editorial Universitaria de la Universidad Nacional Federico Villarreal.

Cornejo Polar, A. (1989). La formación de la tradición literaria en el Perú. Lima: Centro de Estudios y Publicaciones.

Cuba, M. del C. (1999). Monólogo desde las tinieblas: lengua, literatura y cosmovisión de los negros de Chincha. Escritura y Pensamiento, 2, 3, 9-44.

Espino Relucé, G. (2010). La literatura oral o la literatura de tradición oral. Lima: Pakarina Editores, Facultad de Letras y Ciencias Humanas de la Universidad Nacional Mayor de San Marcos. 
Gálvez Ronceros, A. (1962). Los ermitaños. Lima: Difusora Cultural Peruana.

Gálvez Ronceros, A. (1975). Monólogo desde las tinieblas. Lima: Inti Sol Editores.

Gálvez Ronceros, A. (2017). Monólogo desde las tinieblas. Lima: Alfaguara.

García Miranda, C. (2009). Utopía negra. Representación, escritura/oralidad e identidad cultural en la narrativa negrista de Antonio Gálvez Ronceros. Lima: Fondo Editorial de la Facultad de Letras y Ciencias Humanas de la Universidad Nacional Mayor de San Marcos.

Laporte, D. (1998). Historia de la mierda. Madrid: Pre-textos.

Levin, H. (1974). El realismo francés. Stendhal, Balzac, Flaubert, Zola, Proust. Barcelona: Editorial Laia.

López Albújar, E. (1973 [1928]). Matalaché. Lima: Peisa.

Macedo Janto, G. (2008). Canto de sirena: oralidad y memoria. Lima: Hipocampo editores.

Martínez, G. (1975). Tierra de caléndula. Lima: Ediciones Milla Batres.

Martínez, G. (1979 [1977]). Canto de sirena, segunda edición. Lima: Mosca Azul editores.

Mudarra Montoya, A. (2013). El Joche se ha ido. Marginalidad e ideología en "Joche" de AGR. Martín. Revista de Artes \& Letras de la Universidad San Martín de Porres, 26, 77-82.

N'gom, M. (2008). “Escribir” la identidad: creación cultural y negritud en el Perú. Lima: Editorial Universitaria de la Universidad Ricardo Palma.

Olaya Rocha, J. M. (2017). Lucía Charún-Illescas, la primera novelista afroperuana. Recuperado de https://afroliteratura.lamula.pe/2017/01/19/ lucia-charun-illescas-la-primera-novelista-afroperuana/afroliteratura. lamula.pe/.

Ong, W. (2009). Oralidad y escritura: tecnologías de la palabra. Ciudad de México: Fondo de Cultura Económica.

Orihuela, C. L. (2009). La heterogeneidad negrista en la literatura peruana: el caso de Monólogo desde las tinieblas de Antonio Gálvez Ronceros. En C. L. 
Negritud, oralidad y carnaval en la narrativa afrodescendiente peruana del siglo XX

(Gálvez Ronceros, Martínez y Charún-Illescas): hacia la conformación de un corpus autónomo

Orihuela, Abordajes y aproximaciones. Ensayos sobre literatura peruana del siglo XX (1950-2001) (pp. 37-54). Lima: Hipocampo editores, Escuela de Postrado de la Universidad Nacional Mayor de San Marcos.

Quiroz, V. (2013). Claves para una lectura bajtiniana de Monólogo desde las tinieblas. R. Leonardo (Ed.), Poéticas de lo negro. Literatura y otros discursos acerca de lo afroperuano en el siglo XX (pp. 82-93). Lima: Hipocampo editores.

Solís, J. (2013). Hacia una poética de la transcripción. Comentario de tres cuentos de Monólogo desde las tinieblas de AGR. Martín. Revista de Artes \& Letras de la Universidad San Martín de Porres, 26, 85-95.

Terán Morveli, J. (2008). ¿Desde dónde hablar? Dinámicas oralidad-escritura. Lima: Andes Books.

Velázquez Castro, M. (2005). Las máscaras de la representación. El sujeto esclavista y las rutas del racismo en el Perú (1775-1895). Lima: Fondo Editorial de la Universidad Nacional Mayor de San Marcos, Banco Central de Reserva del Perú.

Vich, V. \& Zavala, V. (2004). Oralidad y poder: herramientas metodológicas. Bogotá: Norma.

Volóshinov, V. N. (2009). El marxismo y la filosofía del lenguaje. Buenos Aires: Ediciones Godot.

Werner, F. (2013). La materia oscura. Historia cultural de la mierda. Barcelona: Tusquets. 